\title{
Evaluation of Aquaporins 1 and 5 Expression in Rat Parotid Glands After Volumetric Modulated Arc Radiotherapy and Use of Low-Level Laser Therapy at Different Times
}

\author{
Gabriel Francisco Krueger', Milene Castilhos de Oliveira', Humberto Thomazi Gassen', Juliana Tomaz \\ Sganzerla', Daniel Simon², Ivana Grivicich ${ }^{2}$, Pedro Antonio González Hernández ${ }^{3}$, Sergio Augusto Quevedo \\ Miguens-Jr ${ }^{{ }^{*}}$ \\ ${ }^{1}$ Department of Oral Medicine, Graduate Program in Dentistry, Universidade Luterana do Brasil, Canoas, RS, Brazil \\ ${ }^{2}$ Graduate Program in Cellular and Molecular Biology Applied to Health, Universidade Luterana do Brasil, Canoas, RS, Brazil \\ ${ }^{3}$ Department of Oral Surgery, Graduate Program in Dentistry, Universidade Luterana do Brasil, Canoas, RS, Brazil
}

\section{*Correspondence to Sergio Augusto Quevedo Miguens-Jr, Av. Farroupilha, 8001, Department of Oral Medicine, Graduate Program in Dentistry, Universidade Luterana do Brasil. Canoas, RS, Brazil, postal code 92425-900. \\ Tel: +55 5134629512 ; E-mail: samiguens@gmail.com; gfrankru@gmail.com}

Published online June 21, 2020

\begin{abstract}
Introduction: This experimental study investigated the mRNA expression of aquaporins (AQPs) 1 and 5 in the parotid glands of rats irradiated with volumetric modulated arc therapy (VMAT) and subjected to low-level laser therapy (LLLT) at different time points.

Methods: The sample consisted of 30 Wistar rats (Rattus norvegicus) divided into the following groups: control, LLLT alone (LG), radiotherapy alone (RG), and experimental groups that received LLLT at 24 hours (early experimental group [EEG], $\mathrm{n}=12$ ) and 120 hours (late experimental group [LEG], $\mathrm{n}=12$ ) after radiotherapy. VMAT was delivered at a single dose (12 Gy) and LLLT was performed with an aluminium-gallium-arsenide diode laser $(660 \mathrm{~nm}, 100 \mathrm{~mW})$, spot area of $0.0028 \mathrm{~cm} 2$, energy of $2 \mathrm{~J} / \mathrm{cm}^{2}$ applied to 3 spots in the region corresponding to the right parotid gland, for 10 consecutive days. The right parotid gland was resected and prepared for RNA extraction. The gene expression of AQPs was evaluated by quantitative polymerase chain reaction (qPCR) using specific TaqMan probes, with the HPRT gene as an internal control. Results: The lowest AQP1 gene expression was 0.83 (0.27) with the use of LLLT 24 hours after radiotherapy (EEG), and the highest was $1.56(0.80)$ with the use of LLLT alone (LG). Likewise, the lowest AQP5 gene expression was found in the EEG (mean $=0.88 ; \mathrm{SD}=0.49)$ and the highest in the LG (mean = 1.29; SD =0.33).

Conclusion: The use of LLLT after radiotherapy may contribute to the maintenance and an increase of these proteins, even when used at a later time point after radiotherapy.

Keywords: Aquaporins; Salivary glands; Intensity-modulated radiotherapy; Low-level light therapy; Rats.
\end{abstract}

\section{Introduction}

Xerostomia due to radiotherapy-induced hyposalivation, one of the main clinical complications of cancer therapy, is caused by the action of ionising radiation on cellular structures of the salivary glands. ${ }^{1,2}$ Because the salivary glands are in the radiation field in most cases of treatment of head and neck cancer, radiation causes atrophy and apoptosis of fluid-secreting acinar cells..$^{3-5}$ Volumetric modulated arc therapy (VMAT) has shown more effective results and less damage to the normal tissue than other radiotherapy modalities, with the dose and frequency delivered in fractions and directed to the target tissue. ${ }^{6,7}$ Among the treatment modalities used to improve the sequelae of radiotherapy to the salivary glands, low- level laser therapy (LLLT) has produced favourable results in terms of tissue repair and biomodulation of the inflammatory process, ${ }^{8-13}$ especially in clinical and histological studies evaluating the effects of LLLT on the salivary glands in the ionising radiation field. ${ }^{14-17}$

Damage caused by radiotherapy to the stroma and structures involved in the process of salivary secretion has a direct impact on salivary production and flow. Water transport by the acinar cells for primary production of saliva occurs through specific proteins, namely aquaporins (AQPs). AQPs form a family of proteins with 13 different molecular structures, each of which is present in a particular tissue type and performs specific functions associated with water and solute transport. ${ }^{18-20}$ In addition

Please cite this article as follows: Krueger GF, de Oliveira MS, Gassen HT, Sganzerla JT, Simon D, Grivicich I, et al. Evaluation of aquaporins 1 and 5 expression in rat parotid glands after volumetric modulated arc radiotherapy and use of low-level laser therapy at different times. J Lasers Med Sci. 2020;11(3):262-267. doi:10.34172/jlms.2020.44. 
to being involved in the processes of cell proliferation, migration, and apoptosis, these transmembrane proteins consist of water channels present in the cell membrane of several tissues, contributing to transepithelial water movement. ${ }^{21-23}$

In the major salivary glands, AQP1 and AQP5 are strongly associated with water transport and fluid secretion; therefore, the functional and structural integrity of these proteins must be preserved. ${ }^{9,24}$ AQPs present in the membrane of the acinar cells and duct cells may be affected by radiotherapy, thus modifying the dynamics of the salivary secretion process. ${ }^{25}$

Previous studies in animal models investigating the mechanisms of action and participation of AQPs in the process of salivary secretion in relation to the physiology ${ }^{18,26}$ and maintenance of these proteins in the salivary glands after cobalt $60\left(\mathrm{Co}^{60}\right)$ radiotherapy ${ }^{25}$ have demonstrated the down-regulation of AQP expression. However, the effects of using VMAT radiotherapy and LLLT on the expression of AQPs in the major salivary glands have not yet been reported, especially regarding the potential action of LLLT on the synthesis of nucleic acids and proteins, which may lead to increased expression of AQPs in the plasma membrane, thereby facilitating water permeability during the process of salivary flow.

Therefore, this study aimed to investigate AQP1 and AQP5 mRNA expression in the parotid glands of rats irradiated with VMAT and subjected to LLLT at early (24 hours) and late (120 hours) time points after radiotherapy.

\section{Methods}

This experimental study in an animal model is part of a project approved by the Animal Care and Use Committee of Universidade Luterana do Brasil (approval number 201410P). Animal handling and experimentation followed the Brazilian ethical principles of animal experimentation and international standards and guidelines for the care and use of laboratory animals. All efforts were made to minimise pain and discomfort, as well as to use only the minimum number of animals required to produce reliable scientific data.

The sample consisted of the right parotid glands of 30 adult (7- to 8-week-old) male Wistar rats (Rattus norvegicus) weighing 240 to $300 \mathrm{~g}$ each. The rats were randomly divided into five groups as shown in Figure 1.

The groups were divided into one control group that received no intervention (CG), one that received radiotherapy alone $(\mathrm{RG})$, one that received LLLT alone

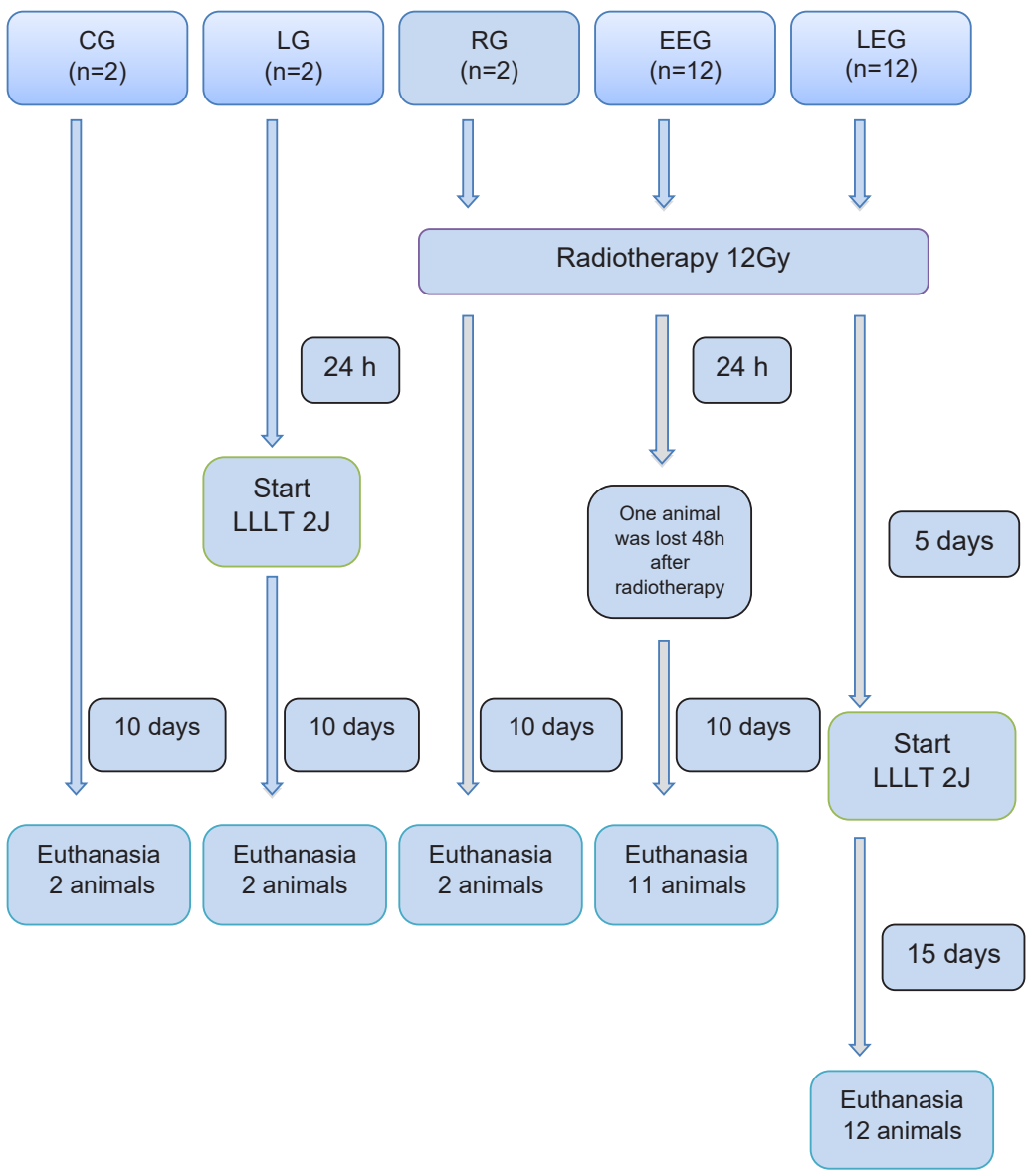

Figure 1. Flow Diagram of Group Distribution and Interventions.

Legend: LLLT (low-level laser therapy); CG (control group); LG (laser group); RG (radiotherapy group); EEG (early experimental group); LEG (late experimental group). 
(LG), and two experimental groups that received LLLT at 24 hours (early experimental group [EEG]) and 120 hours (late experimental group [LEG]) after radiotherapy. One animal in the EEG was lost 48 hours after radiotherapy, resulting in a total sample of 29 parotid glands for analysis.

Animals in the groups receiving radiotherapy (RG, EEG, and LEG) were subjected to VMAT delivered with a Trilogy linear accelerator (Varian Medical Systems, Palo Alto, CA, USA) at a single dose of 12 Gy with $6 \mathrm{MV}$ photons and a radiation field of $9 \times 40 \mathrm{~cm}^{2}$, at $1 \mathrm{~cm}$ in diameter from the head region (Figure $2 \mathrm{a}$ ).

Animals in the groups receiving LLLT (LG, EEG, and LEG) were subjected to the same laser irradiation protocol. At a distance of $1 \mathrm{~cm}$ from the external area corresponding to the right parotid gland (Figure $2 \mathrm{~b}$ ), the laser was applied to three spots with an aluminiumgallium-arsenide diode laser (Photon Lase III DMC Ltda) at a wavelength of $660 \mathrm{~nm},{ }^{27} 100 \mathrm{~mW}$ output power, spot area of $0.0028 \mathrm{~cm}^{2}$, and energy density of $2 \mathrm{~J} / \mathrm{cm}^{2}$ over an irradiation time of 20 seconds per spot, for a total of 60 seconds and $70 \mathrm{~J} / \mathrm{cm}^{2} / \mathrm{d}$ for 10 consecutive days.

Rats were euthanised by intraperitoneal administration of barbiturate and local anaesthetic (thiopental and lidocaine) at a concentration of $80 \mathrm{mg} / \mathrm{kg}$ at different time points, according to the distribution of the experimental groups (Figure 1), always 24 hours after the last LLLT application. In the CG, LG, and RG, euthanasia was performed at the same time as in the EEG.

Subsequently, the right parotid gland was resected and stored in a tube containing RNA stabilisation solution (RNAlater; Ambion, Applied Biosystems, Carlsbad, CA, USA) for later analysis by quantitative polymerase chain reaction (qPCR) in a thermal cycler (StepOnePlus ${ }^{\mathrm{TM}}$ Real-Time PCR System; Life Technologies, Carlsbad, CA, USA). DNA was extracted from the cells according to the conventional silica-based process after individually grinding each sample. ${ }^{28}$

The DNA fragments were amplified by qPCR using probes specific to AQPs (Integrated DNA Technologies Inc., Coralville, IA, USA) under the following conditions: $95^{\circ} \mathrm{C}$ for 3 minutes, then 40 cycles of $95^{\circ} \mathrm{C}$ for 15 seconds and $60^{\circ} \mathrm{C}$ for 1 minute. The hypoxanthine

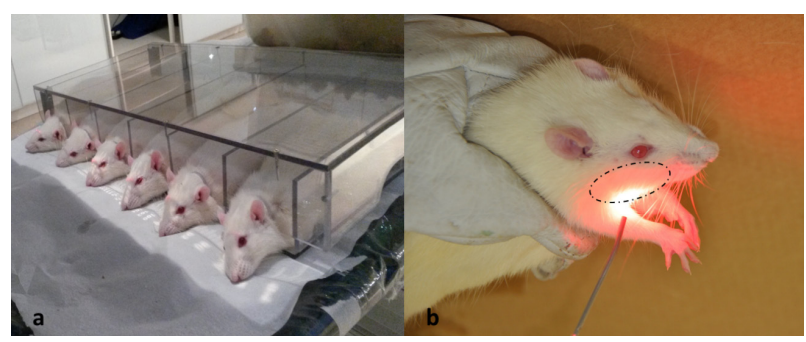

Figure 2. (a) Rat positioning for radiotherapy protocol with VMAT using a Trilogy linear accelerator. (b) Low-level laser irradiation protocol with the laser applied to three spots at a distance of $1 \mathrm{~cm}$ from the area corresponding to the right parotid gland. phosphoribosyltransferase (HPRT) gene was used as an internal control.

The expression of mRNA was analysed by using kits with RNA-specific primers. The samples were rotated 40 times to obtain a higher number of cycles and to improve data accuracy. ${ }^{5}$ All qPCR procedures were performed by a single examiner with experience in the method, who was blinded to group assignment (the groups were coded for analysis).

The $2^{-\Delta \Delta \mathrm{Ct}}$ algorithm was used to analyse the data obtained from AQP1 and AQP5 expression assays in all groups for quantification of the mean relative expression levels per group, which were then compared to the control group (CG). The Mann-Whitney $U$ test was used to analyse the results, and a $P$ value $<0.05$ was considered significant.

\section{Results}

The analysis of the mRNA expression of AQP1 and AQP5 by qPCR showed a mean value of 1.0 for both types in the $\mathrm{CG}$, which was used as a reference value for comparisons with the other groups (Table 1).

The lowest AQP1 gene expression was 0.83 (0.27) with the use of LLLT 24 hours after radiotherapy (EEG), and the highest was $1.56(0.80)$ with the use of LLLT alone (LG). The highest expression of AQP1 was in the groups using LLLT alone (LG) and late use after radiotherapy (LEG).

Likewise, the lowest AQP5 gene expression was found in the EEG (mean $=0.88$; SD =0.49), and the highest in the LG (mean $=1.29 ; \mathrm{SD}=0.33$ ) (Table 1). In the comparison between the groups, the average expression of AQP5 was higher in the LG group which used only LLLT. In summary, the mean values obtained for the mRNA expression of AQP1 and AQP5 showed little variation among the treatments, with no statistically significant difference between the groups.

\section{Discussion}

AQP1 and AQP5 were expressed in all samples of parotid glands, regardless of group assignment. However, AQP1 showed the highest mean expression levels, especially in the samples from the groups that received LLLT, whether with or without previous radiotherapy. Mean AQP5 expression was highest in the group that received LLLT alone, however, without statistical significance. Studies evaluating gene expression by qPCR after the use of LLLT have shown conflicting results regarding its effect. ${ }^{29}$

These results may be related to the heterogeneity of sample composition, given that the samples included the entire anatomical structure of the salivary glands rather than only the sites where the proteins were located, and also to the preparation of samples for qPCR, which were ground without separating the acini from the ducts. This may have contributed to the different mean expression 
Table 1. Distribution of the Mean (SD) mRNA Expression of AQP1 and AQP5 in the Different Groups Compared to the Control Group (CG)

\begin{tabular}{|c|c|c|c|c|}
\hline Groups & AQP1 Expression Mean (SD) & $\boldsymbol{P}$ & AQP5 Expression Mean (SD) & $\boldsymbol{P}$ \\
\hline RG & $0.98(0.27)$ & 0.922 & $1.16(0.54)$ & 0.715 \\
\hline LG & $1.56(0.80)$ & 0.363 & $1.29(0.33)$ & 0.102 \\
\hline EEG & $0.83(0.27)$ & 0.423 & $0.88(0.49)$ & 0.553 \\
\hline LEG & $1.11(0.31)$ & 0.608 & $0.90(0.37)$ & 0.667 \\
\hline
\end{tabular}

RG, Radiotherapy group; LG, LLLT group; EEG, Early experimental group; LEG, Late experimental group.

values observed among the groups and represented by their respective standard deviations. However, studies have shown that AQP1 expression in the salivary glands is higher in ductal cells than in myoepithelial cells, while AQP5 expression is higher in the basal cells of the acini at different sites. ${ }^{25,26,30-33}$

The groups receiving radiotherapy did not differ in AQP expression from the control group in contrast to previous reports that these proteins are radiosensitive, especially AQP5. ${ }^{25}$ However, the radiotherapy modality used should be taken into consideration. For instance, conventional $\mathrm{Co}^{60}$ radiotherapy is often associated with greater tissue damage and less selectivity than VMAT, the modality used in the present study. Also, in the study conducted by Li et al, ${ }^{25}$ qPCR performed on days 3 and 30 after radiotherapy showed a progressive decrease in AQP5 expression levels. This is different from our results, which showed that mean AQP5 expression levels remained superior in the group that received LLLT at a later time point compared to the control group.

The group receiving LLLT alone had the highest mean AQP expression values. This result may be associated with the different actions of laser irradiation on the salivary glands. Simões et $\mathrm{al},{ }^{33}$ evaluating the effects of the infrared diode laser, found an increase in protein synthesis in the parotid and submandibular glands of healthy rats compared to the control group. This may be attributed to photobiological reactions induced by LLLT on glandular tissues, which may occur in the presence or absence of light. In the latter, this may occur days after laser irradiation, leading to biochemical changes in the cells that modify the mitochondrial respiratory chain and activate intracellular signalling, which increases DNA and RNA synthesis, thereby increasing cell proliferation and protein synthesis. ${ }^{34-36}$

The group receiving LLLT 24 hours after radiotherapy had lower mean AQP expression values than the group receiving LLLT at a later time point. This may be related to a cellular stress adaptive response caused by the immediate use of the laser, without sufficient time for adequate tissue repair. Conversely, if a longer time is allowed for tissue repair, the subsequent use of LLLT can lead to the modulation of the inflammatory process and activation of transcription factors, which promote the growth of fibroblasts, pro-inflammatory cytokines, and chemokines involved in tissue repair. ${ }^{14,33,36-38}$

This study has some limitations that need to be addressed. A healthy animal model was used, without simulation or presence of malignancy, which appears to have promoted a selective effect, or even a protective effect, of VMAT. This radiotherapy modality is able to minimise frequency, dose, and toxicity to the normal tissue by being directed to the neoplastic cells. ${ }^{6,7}$ Also, we were unable to perform a qualitative analysis of the cells and gland parenchyma, thus precluding the determination of the exact location of AQPs in the parotid glands. The method used for obtaining the samples required grinding of the tissues to perform qPCR, which is a quantitative method for mRNA analysis. Therefore, further studies using other types of analysis are still needed to determine the location and structure of AQPs in order to clarify how LLLT acts on the salivary glands after radiotherapy. The use of immunohistochemistry seems to be an effective option for evaluating the location and structure of AQPs in the salivary glands. ${ }^{25,39,40-42}$

To date, no studies have been published reporting the expression of AQP1 and AQP5 in salivary glands (without separating the acini from the ducts) irradiated with VMAT and subjected to LLLT at different time points. Therefore, the present results are expected to provide a basis for future studies analysing AQPs in the salivary glands that are in the radiation field using different radiotherapy modalities, doses and LLLT protocols, in an attempt to establish an effective therapy for the management of xerostomia due to radiotherapyinduced hyposalivation.

\section{Conclusion}

The use of LLLT seems to contribute even to an increase of AQP1 and AQP5 in the rat's parotid gland even when used at a later time point after radiotherapy for VMAT. The results suggest that the use of LLLT contributes to the maintenance of the salivary secretion process.

\section{Ethical Considerations}

This study has been approved by the Animal Care and Use Committee of Universidade Luterana do Brasil - RS/ Brazil (CEUA/ULBRA; approval number 2014-10P).

\section{Conflict of Interests}

The authors declare that they have no conflict of interest.

\section{References}

1. Saleh J, Figueiredo MA, Cherubini K, Salum FG. Salivary 
hypofunction: An update on aetiology, diagnosis and therapeutics. Arch Oral Biol. 2014;60(2):242-255. doi: 10.1016/j.archoralbio.2014.10.004.

2. Bahl A, Oinam AS, Kaur S, Verma R, Elangovan A, Bhandari S, et al. Evaluation of acute toxicity and early clinical outcome in head and neck cancers treated with conventional radiotherapy and simultaneous integrated boost arc radiotherapy. World J Oncol. 2017;8(5):174. doi: 10.14740/wjon1049wc1.

3. Vissink A, Jansma J, Spijkervet FK, Burlage FR, Coppes RP. Prevention and Treatment of the Consequences of Head and Neck Radiotherapy. Crit Rev Oral Biol Med. 2003;14(3):199-212. doi: 10.1177/154411130301400305

4. Freitas DA, Caballero AD, Pereira MM, Oliveira SK, Silva GP, Hernández CI. Oral sequelae of head and neck radiotherapy. Rev CEFAC. 2011;13(6):1103-1108. doi: 10.1590/s1516-18462011005000071.

5. Baum BJ, Zheng C, Cotrim AP, Goldsmith CM, Atkinson JC, Brahim JS, et al. Transfer of the AQP1 cDNA for the correction of radiation-induced salivary hypofunction. Biochim Biophys Acta Biomembr. 2006;1758(8):1071-1077. doi: 10.1016/j.bbamem.2005.11.006.

6. Lee SW, Kang KW, Wu HG. Prospective investigation and literature review of tolerance dose on salivary glands using quantitative salivary gland scintigraphy in the intensitymodulated radiotherapy era. Head Neck. 2016;38(Suppl 1):E1746-55. doi: 10.1002/hed.24310.

7. Van Gestel D, Van Den Weyngaert D, Schrijvers D, Weyler J, Vermorken JB. Intensity-modulated radiotherapy in patients with head and neck cancer: A European singlecentre experience. Br J Radiol. 2011;84(1000), 367-374. doi: 10.1259/bjr/67058055.

8. França CM, França CM, Núñez SC, Prates RA, Noborikawa E, Faria MR, et al. Low-intensity red laser on the prevention and treatment of induced-oral mucositis in hamsters. $J$ Photochem Photobiol B. 2009;94(1):25-31. doi: 10.1016/j. jphotobiol.2008.09.006.

9. González-Arriagada WA, Ramos LMA, Andrade MAC, Lopes MA. Efficacy of low-level laser therapy as an auxiliary tool for management of acute side effects of head and neck radiotherapy. J Cosmet Laser Ther. 2018;20(2):117-122. doi: 10.1080/14764172.2017.1376097.

10. Lončar B, Stipetić MM, Baričević M, Risović D. The effect of low-level laser therapy on salivary glands in patients with xerostomia. Photomed Laser Surg. 2011;29(3):171175. doi: 10.1089/pho.2010.2792.

11. Basirat $M$. The effects of low power lasers in healing of oral ulcers. J Lasers Med Sci. 2012;3(2):79-83. doi: 10.22037/ jlms.v3i2.3209.

12. Fekrazad R, Chiniforush N. Oral mucositis prevention and management by therapeutic laser in head and neck cancers. J Lasers Med Sci. 2014;5(1):1-7. doi:10.22037/jlms. v5i1.5460.

13. Acauan MD, Gomes AP, Braga-Filho A, de Figueiredo MA, Cherubini K, Salum FG. Effect of low-level laser therapy on irradiated parotid glands-study in mice. J Biomed Opt. 2015; 20(10):108002. doi: 10.1117/1.jbo.20.10.108002.

14. Gonnelli FA, Palma LF, Giordani AJ, Deboni AL, Dias RS, Segreto RA, et al. Low-level laser therapy for the prevention of low salivary flow rate after radiotherapy and chemotherapy in patients with head and neck cancer. Radiol Bras. 2016;49(2):86-91. doi: 10.1590/01003984.2014.0144.

15. Plavnik LM, De Crosa ME, Malberti AI. Effect of lowpower radiation (Helium/Neon) upon submandibulary glands. J Clin Laser Med Surg. 2003;21(4):219-225. doi: $10.1089 / 104454703768247792$.

16. Saleh J, Figueiredo MA, Cherubini K, Braga-Filho A, Salum FG. Effect of low-level laser therapy on radiotherapyinduced hyposalivation and xerostomia: A pilot study. Photomed Laser Surg. 2014;32(10):546-552. doi: 10.1089/ pho.2014.3741.

17. Vidović Juras D, Lukač J, Cekić-Arambašin A, Vidović A, Canjuga I, Sikora M, et al. Effects of low-level laser treatment on mouth dryness. Coll Antropol. 2010;34(3):1039-43.

18. Benga G. Water channel proteins (later called aquaporins) and relatives: Past, present, and future. IUBMB Life. 2009;61(2):112-33. doi: 10.1002/iub.156.

19. Delporte C, Steinfeld S. Distribution and roles of aquaporins in salivary glands. Biochim Biophys Acta Biomembr. 2006;1758(8):1061-70. doi: 10.1016/j. bbamem.2006.01.022.

20. Delporte C, Bryla A, Perret J. Aquaporins in salivary glands: From basic research to clinical applications. Int $J$ Mol Sci. 2016;17(2):166. doi: 10.3390/ijms17020166.

21. Aure MH, Ruus AK, Galtung HK. Aquaporins in the adult mouse submandibular and sublingual salivary glands. $J$ Mol Histol. 2014;45(1):69-80. doi: 10.1007/s10735-0139526-3.

22. Hosoi K. Physiological role of aquaporin 5 in salivary glands. Pflugers Arch. 2016;468(4):519-39. doi: 10.1007/ s00424-015-1749-6.

23. Ishikawa Y, Cho G, Yuan Z, Inoue N, Nakae Y. Aquaporin-5 water channel in lipid rafts of rat parotid glands. Biochim Biophys Acta Biomembr. 2006;1758(8):1053-60. doi: 10.1016/j.bbamem.2006.03.026.

24. Piva JA, Abreu EM, Silva Vdos S, Nicolau RA. Effect of low-level laser therapy on the initial stages of tissue repair: basic principles. An Bras Dermatol. 2011;86(5), 947-954. doi: 10.1590/s0365-05962011000500013.

25. Li Z, Zhao D, Gong B, Xu Y, Sun H, Yang B, et al. Decreased saliva secretion and down-regulation of AQP5 in submandibular gland in irradiated rats. Radiat Res. 2006;165(6):678-687. doi: 10.1667/rr3569.1.

26. Larsen HS, Ruus AK, Galtung HK. Aquaporin expression patterns in the developing mouse salivary gland. Eur J Oral Sci. 2009;117(6):655-662. doi: 10.1111/j.16000722.2009.00695.x.

27. Bjordal JM, Bensadoun RJ, Tunèr J, Frigo L, Gjerde K, Lopes-Martins RA. A systematic review with meta-analysis of the effect of low-level laser therapy (LLLT) in cancer therapy-induced oral mucositis. Support Care Cancer. 2011;19(8):1069-77. doi: 10.1007/s00520-011-1202-0.

28. Boom R, Sol CJ, Salimans MM, Jansen CL, WertheimVan Dillen PM, van der Noordaa J. Rapid and simple method for purification of nucleic acids. J Clin Microbiol. 1990;28(3):495-503.

29. Bomfim FRC, Sella VRG, Thomasini RL, Plapler H. Influence of low-level laser irradiation on osteocalcin protein and gene expression in bone tissuel. Acta 
Cir Bras. 2018;33(9):736-743. doi: 10.1590/s0102865020180090000001.

30. Sugimoto N, Matsuzaki K, Ishibashi H, Tanaka M, Sawaki T, Fujita $\mathrm{Y}$, et al. Upregulation of aquaporin expression in the salivary glands of heat-acclimated rats. Sci Rep. 2013;3:1763. doi: 10.1038/srep01763.

31. Araujo MVT, Spadella MA, Chies AB, Arruda GV, Santos TM, Cavariani MM, et al. Effect of low radiation dose on the expression and location of aquaporins in rat submandibular gland. Tissue Cell. 2018;53:104-110. doi: 10.1016/j.tice.2018.06.006.

32. de Paula F, Teshima THN, Hsieh R, Souza MM, CoutinhoCamillo CM, Nico MMS, et al. The expression of water channel proteins during human salivary gland development: a topographic study of aquaporins 1, 3 and 5. J Mol Histol. 2017; 48(5):329-336. doi: 10.1007/s10735017-9731-6.

33. Simões A, Siqueira WL, Lamers ML, Santos MF, Eduardo Cde P, Nicolau J. Laser phototherapy effect on protein metabolism parameters of rat salivary glands. Lasers Med Sci. 2009;24(2):202-208. doi: 10.1007/s10103-008-0548-0.

34. Pan Y, Iwata F, Wang D, Muraguchi M, Ooga K, Ohmoto Y, et al. Identification of aquaporin-5 and lipid rafts in human resting saliva and their release into cevimeline-stimulated saliva. Biochim Biophys Acta Gen Subj. 2009;1790(1):49-56. doi: 10.1016/j.bbagen.2008.08.009.

35. Karu TI. Multiple roles of cytochrome $\mathrm{c}$ oxidase in mammalian cells under action of red and IR-A radiation. IUBMB Life. 2010;62(8):607-10. doi: 10.1002/iub.359

36. Zecha JA, Raber-Durlacher JE, Nair RG, Epstein JB, Elad S, Hamblin MR, et al. Low-level laser therapy/ photobiomodulation in the management of side effects of chemoradiation therapy in head and neck cancer: part 2: proposed applications and treatment protocols. Support Care Cancer. 2016;24(6):2793-2805. doi: 10.1007/s00520016-3153-y.

37. de Freitas LF, Hamblin MR. Proposed Mechanisms of Photobiomodulation or Low-Level Light Therapy. IEEE J Sel Top Quantum Electron. 2016;22(3). doi: 10.1109/ JSTQE.2016.2561201.

38. Lins RD, Dantas EM, Lucena KC, Catão MH, GranvilleGarcia AF, Carvalho Neto LG. Biostimulatory effects of low power laser in the repair process. An Bras Dermatol. 2010;85(6):849-55. doi: 10.1590/S036505962010000600011.

39. Gresz V, Burghardt B, Ferguson CJ, Hurley PT, Takács $\mathrm{M}$, Nielsen S, et al. Expression of aquaporin 1 (AQP1) water channels in human labial salivary glands. Arch Oral Biol. 1999;44(Suppl 1):S53-S7. doi: 10.1016/S00039969(99)90020-1.

40. Gresz V, Kwon TH, Gong H, Agre P, Steward MC, King LS, et al. Immunolocalization of AQP-5 in rat parotid and submandibular salivary glands after stimulation or inhibition of secretion in vivo. Am J Physiol Gastrointest Liver Physiol. 2004;287(1):G151-61. doi: 10.1152/ ajpgi.00480.2003.

41. Tatsuishi Y, Hirota M, Kishi T, Adachi M, Fukui T, Mitsudo $\mathrm{K}$, et al. Human salivary gland stem/progenitor cells remain dormant even after irradiation. Int J Mol Med. 2009;24(3):361-366. doi: 10.3892/ijmm_00000240.

42. Gresz V, Horvath A, Gera I, Nielsen S, Zelles T. Immunolocalization of AQP5 in resting and stimulated normal labial glands and in Sjögren's syndrome. Oral Dis. 2015;21(1):e114-e120. doi: 10.1111/odi.12239. 